\title{
Dysregulation of the RANKL/RANK/OPG axis in thalassemia intermedia patients
}

\author{
Mahmoud A. Alfaqih ${ }^{1 *} \mathbb{D}$, Nabil Bashir ${ }^{1}$, Rami Saadeh², Yousef Khader ${ }^{2}$, Musa Barqawi $^{3}$ and Sara Alqudah ${ }^{1}$
}

\begin{abstract}
Objective: Thalassemia intermedia (TI) describes a disease ranging in severity between $\beta$ thalassemia major (TM) and $\beta$ thalassemia trait. Osteoporosis is observed in TI and TM. The exact reason of osteoporosis in TI could be hypogonadism and/or an increase in erythropoietin (EPO) levels. The carboxy-terminal collagen cross links (CTX), a marker of bone resorption, and the N-terminal propeptide of type 1 collagen (P1NP), a marker of bone formation are serum markers of osteoporosis. The receptor activator of NF-kappaB ligand (RANKL)/receptor activator of NF-kappaB (RANK)/ osteoprotegerin (OPG) axis plays an important role in metabolic bone diseases. Herein, we tested the relationship between the RANKL/RANK/OPG axis and the bone-turnover markers CTX and P1NP in TI.

Results: We recruited $44 \mathrm{TI}$ patients and 33 non-thalassemic controls and measured the serum levels of hemoglobin, sex steroid hormones, CTX, P1NP, RANKL and OPG. We then used a general linear model to test the association of the above variables with CTX and P1NP as outcome variables. We showed that EPO levels were the strongest predictor of CTX change $(P<0.000)$, followed by RANKL $(P=0.017)$. On the other hand, RANKL was the strongest predictor of P1NP change $(P<0.000)$, followed by OPG $(P=0.009)$ and $E P O(P=0.024)$.
\end{abstract}

Keywords: Thalassemia intermedia, Osteoporosis, Bone mineral density, Receptor activator of NF-kappaB ligand, Osteoprotegerin

\section{Introduction}

Thalassemia intermedia (TI) is a term that describes $\beta$ thalassemia patients in which the manifestations range in severity between $\beta$ thalassemia major (TM) and $\beta$ thalassemia trait $[1,2]$. Among the complications associated with TI, osteoporosis is common [3]. The cause of osteoporosis is multifactorial and could be influenced by hypogonadism [4], increased erythropoietin (EPO) levels, bone marrow expansion [5], vitamin D and calcium deficiency [6]. An understanding of how the above factors determine bone loss in TI is important for the development of novel therapeutics.

Several serum markers are used in the diagnosis of osteoporosis and in monitoring response to treatment in individuals with metabolic bone diseases including thalassemia [7]. The carboxy terminal collagen cross links

\footnotetext{
*Correspondence: maalfaqih@just.edu.jo

${ }^{1}$ Department of Physiology and Biochemistry, School of Medicine, Jordan University of Science and Technology, Irbid 22110, Jordan

Full list of author information is available at the end of the article
}

(CTX), a marker of bone resorption, and the $\mathrm{N}$-terminal propeptide of type 1 collagen (P1NP), a marker of bone formation are commonly used [7]. Their use as bone turnover markers was endorsed by the International Osteoporosis Foundation [8].

The receptor activator of NF-kappaB ligand (RANKL)/ receptor activator of NF-kappaB (RANK)/Osteoprotegerin (OPG) axis has received attention for the central role it plays in regulating bone mass density $[9,10]$. RANKL is a cytokine secreted by osteoblasts in response to low calcium levels [11]. RANKL activates osteoclast differentiation from pre-osteoclasts through binding to its receptor, RANK, found on the surface of pre-osteoclasts [11]. OPG inhibits bone loss by acting as a decoy receptor to RANKL and preventing it from binding to RANK $[11,12]$. Despite reports that discussed a role for the RANKL/RANK/OPG axis in determining bone loss in TM $[13,14]$, the contribution of this axis to bone loss in TI was not investigated. Establishing a role for the above axis in bone loss in TI will highlight its importance as a biomarker for the diagnosis of osteoporosis in this 
group of patients and for monitoring the response of treatment to bone anti-resorptive therapy.

\section{Main text \\ Methods \\ Subjects}

This was a comparative study carried out on TI patients attending the Thalassemic unit of Princess Rahma hospital in Irbid, Jordan. Recruitment took place between March 2015 and April 2016. Diagnosis with TI was confirmed by a pediatric hematologist based on having a hemoglobin level of 6-7 g/dl and maintaining this level without regular blood transfusions. Diabetic patients, patients with thyroid or liver disease, patients taking steroids, anticonvulsant therapies, vitamin D supplements, bisphosphonates and iron chelation therapy were excluded from both arms of the investigation. Nonthalassemic subjects were attending other clinics of the above tertiary hospital. Absence of thalassemia, hemoglobinopathies or any other blood related disorder was confirmed through hemoglobin level measurements and hemoglobin electrophoresis. Written Informed consents were obtained from all participants, or their legal guardians, according to the regulations of the Institutional Review Boards of Jordan University of Science and Technology and Princess Rahma Hospital.

\section{Sample collection and processing}

Two blood samples (5 $\mathrm{ml}$ each) were collected from each subject that met our criteria above. One sample was collected in a plain tube with a gel and clot activator (AFCO, Jordan) and another sample collected in an EDTA tube (AFCO, Jordan). Blood in plain tubes was centrifuged at $4000 \times g$ for $7 \mathrm{~min}$, the serum was recovered from the tubes and aliquoted into Eppendorf tubes later stored at $-80{ }^{\circ} \mathrm{C}$. Blood in EDTA tubes was used to measure hemoglobin.

\section{Hemoglobin levels measurements}

Hemoglobin levels measurements were performed within 15 min after collection. These measurements were performed on an HORIBA ABX Micros 60 Hematology Analyzer (Kyoto, Japan). This analyzer uses the hemiglobincyanide $(\mathrm{HiCN})$ method.

\section{Biochemical analysis}

Serum levels of RANKL, OPG, EPO, CTX and P1NP were measured using a sandwich ELISA according to the manufacturer (Mybiosource, San Diego, CA, USA). Absorbance was determined at $450 \mathrm{~nm}$ on an ELx800 ELISA Reader (BioTek Instruments, Winooski, VT, USA). Serum levels of the steroid sex hormones (estrogen or testosterone) were measured using a competitive based
ELISA (Mybiosource, San Diego, CA, USA). Absorbance was determined as for RANKL, OPG, EPO, CTX and P1NP.

\section{Statistical analysis}

The statistical package for social studies (SPSS) software (version 22, Chicago, IL, USA) was used for statistical analyses. A student t-test was used to examine if significant differences exist in age, hemoglobin, RANKL, OPG, RANKL/OPG ratio, EPO, sex steroid hormones, CTX, P1NP between thalassemic and non-thalassemic subjects. A general linear model was used to test the effect EPO, Estrogen/Testosterone, OPG, RANKL on the two outcome variables (CTX and P1NP). The null hypothesis was rejected if $\mathrm{P}$-value $<0.05$.

\section{Results}

Forty-four patients with TI and 39 non-thalassemic individuals met our criteria. No significant differences existed in gender distribution and in age between the non-thalassemic and thalassemic subjects (Table 1). The biochemical profile showed that thalassemic subjects had higher levels of serum erythropoietin (EPO)

Table 1 Baseline characteristics of thalassemic and nonthlalassemic subjects

\begin{tabular}{|c|c|c|c|}
\hline Variable & Non-thalassemic & Thalassemic & P-value $^{a}$ \\
\hline \multicolumn{4}{|l|}{ Gender (n) } \\
\hline Females & 16 & 15 & 0.515 \\
\hline Males & 23 & 29 & \\
\hline Total & 39 & 44 & \\
\hline Age $(\text { mean } \pm S D)^{b}$ & $24.59 \pm 8.165$ & $23.41 \pm 7.916$ & 0.506 \\
\hline $\mathrm{Hb}, \mathrm{g} / \mathrm{dl}(\text { mean } \pm \mathrm{SD})^{\mathrm{b}}$ & $14.5 \pm 1.42$ & $7.8 \pm 0.71$ & $<0.0001$ \\
\hline $\begin{array}{l}\mathrm{EPO}, \mathrm{ng} / \mathrm{ml} \\
\quad(\text { mean } \pm \mathrm{SD})^{\mathrm{b}}\end{array}$ & $137.7 \pm 81.5$ & $638.4 \pm 272.3$ & $<0.0001$ \\
\hline $\begin{array}{l}\text { Estrogen or tes- } \\
\text { tosterone, } \mathrm{ng} / \mathrm{ml} \\
(\text { Mean } \pm \mathrm{SD})^{\mathrm{b}}\end{array}$ & $2.7 \pm 0.9$ & $0.63 \pm 0.44$ & $<0.0001$ \\
\hline $\begin{array}{l}\mathrm{OPG}, \mathrm{pg} / \mathrm{ml} \\
\quad(\mathrm{mean} \pm \mathrm{SD})^{\mathrm{b}}\end{array}$ & $3931.2 \pm 479.8$ & $3370 \pm 1142.4$ & 0.004 \\
\hline $\begin{array}{l}\text { RANKL, pg/ml } \\
\quad(\text { mean } \pm S D)^{b}\end{array}$ & $2621.9 \pm 578.9$ & $4980.9 \pm 1313.6$ & $<0.0001$ \\
\hline $\begin{array}{l}\text { RANKL/OPG ratio } \\
(\text { mean } \pm S D)^{b}\end{array}$ & $0.7 \pm 0.22$ & $1.66 \pm 0.85$ & $<0.0001$ \\
\hline $\begin{array}{l}\mathrm{P} 1 \mathrm{NP}, \mathrm{pg} / \mathrm{ml} \\
\quad(\mathrm{mean} \pm \mathrm{SD})^{\mathrm{b}}\end{array}$ & $269.4 \pm 127.7$ & $64.4 \pm 52$ & $<0.0001$ \\
\hline $\begin{array}{l}\text { CTX, pg/ml } \\
\quad(\text { mean } \pm S D)^{b}\end{array}$ & $185.9 \pm 53.6$ & $459.2 \pm 120.1$ & $<0.0001$ \\
\hline \multicolumn{4}{|c|}{$\begin{array}{l}\mathrm{Hb} \text { hemoglobin, EPO erythropoietin, OPG osteoprotegerin, RANKL receptor } \\
\text { activator of NF-kappaB ligand, RANK receptor activator of NF-kappaB, P1NP } \\
\mathrm{N} \text {-terminal propeptide of type } 1 \text { collagen, CTX carboxy terminal collagen cross } \\
\text { links }\end{array}$} \\
\hline \multicolumn{4}{|c|}{ a P-values were calculated by the Student's t-test } \\
\hline \multicolumn{4}{|c|}{ b Data are presented as the mean \pm standard deviation } \\
\hline
\end{tabular}


$(638.4 \pm 272.3$ vs. $\quad 137.7 \pm 81.5 \mathrm{ng} / \mathrm{ml}, \quad \mathrm{P}<0.0001)$, RANKL $\quad(4980.9 \pm 1313.6$ vs. $2621.9 \pm 578.9 \mathrm{pg} / \mathrm{ml}$, $\mathrm{P}<0.0001)$ and CTX $(459.2 \pm 120.1$ vs. $185.9 \pm 53.6 \mathrm{pg} /$ $\mathrm{ml}, \mathrm{P}<0.0001)$. On the other hand, the thalassemic subjects had lower levels of OPG $(3370.0 \pm 1142.4$ vs. $3931.2 \pm 479.8 \mathrm{pg} / \mathrm{ml}, \mathrm{P}=0.004)$, estrogen/testosterone $(0.63 \pm 0.44$ vs. $2.7 \pm 0.9 \mathrm{pg} / \mathrm{ml}, \mathrm{P}<0.0001)$ and $\mathrm{P} 1 \mathrm{NP}$ $(64.4 \pm 52$ vs. $269.4 \pm 127.7 \mathrm{pg} / \mathrm{ml}, \mathrm{P}<0.0001)$ (Table 1$)$. Noteworthy, all the thalassemic subjects had changes in both sex steroid hormone and EPO levels. None of the patients recruited to this study had changes in only one of the above two parameters (data not shown).

Given that RANKL and OPG levels (i.e.: components of the RANKL/RANK/OPG axis) were different in thalassemic compared to non-thalassemic subjects, we then tested the association of RANKL and OPG with the bone-turnover markers CTX and P1NP. To this end, we used a general linear model with CTX and P1NP as outcome variables. RANKL, OPG, EPO and estrogen/testosterone were predictor variables. Our analysis showed that EPO was the strongest predictor of CTX $(\mathrm{P}<0.000)$, followed by RANKL $(\mathrm{P}=0.017)$ and then by estrogen/testosterone ( $\mathrm{P}=0.029)$. OPG was not a significant predictor of CTX change in this analysis (Table 2).

On the other hand, RANKL was the strongest predictor of P1NP change $(\mathrm{P}<0.000)$, followed by OPG $(\mathrm{P}=0.009)$ and EPO $(\mathrm{P}=0.024)$, while estrogen/testosterone was not a significant predictor of P1NP1 change. RANKL and EPO were the only predictors associated with both CTX and P1NP in the model with EPO explaining 15\% of the variation of CTX (Partial Eta squared $=0.152$ ) while RANKL explaining $19.4 \%$ of the variation of P1NP (Partial Eta squared $=0.194$ ) (Table 2).

Table 2 Prediction of changes in CTX and P1NP using a general linear model

\begin{tabular}{|c|c|c|c|c|}
\hline \multirow[t]{2}{*}{ Variables } & \multicolumn{2}{|c|}{$\begin{array}{l}\text { CTX, pg/ml } \\
(330.759 \pm 166.5)\end{array}$} & \multicolumn{2}{|c|}{$\begin{array}{l}\mathrm{P} 1 \mathrm{NP}, \mathrm{pg} / \mathrm{ml} \\
(160.703 \pm 139.9)\end{array}$} \\
\hline & $P$-value ${ }^{a}$ & $\begin{array}{l}\text { Partial Eta } \\
\text { squared }\end{array}$ & P-value ${ }^{a}$ & $\begin{array}{l}\text { Partial Eta } \\
\text { squared }\end{array}$ \\
\hline EPO & $<0.0001$ & 0.152 & 0.024 & 0.064 \\
\hline $\begin{array}{l}\text { Estrogen or } \\
\text { testosterone }\end{array}$ & 0.029 & 0.060 & 0.816 & 0.001 \\
\hline OPG & 0.335 & 0.012 & 0.009 & 0.083 \\
\hline RANKL & 0.017 & 0.071 & $<0.0001$ & 0.194 \\
\hline
\end{tabular}

CTX carboxy terminal collagen cross links, P1NP N-terminal propeptide of type 1 collagen, EPO erythropoietin, OPG osteoprotegerin, RANKL receptor activator of NF-kappaB ligand

a P-values were calculated by a general linear model with CTX and P1NP as outcome variables

\section{Discussion}

The above findings provide evidence on the presence of changes in the levels of several serum markers that could indicate bone loss in TI patients. Changes in the serum levels of these markers are used in other disease conditions, including TM, to establish the presence of osteoporosis. Although premature, these changes are discussed in the context of how they could mechanistically contribute to osteoporosis in TI based on previous reports that discuss the contribution of these markers to bone loss in other disease conditions.

Notable was our finding that the serum levels of the sex steroid hormones estrogen or testosterone were significantly lower in TI patients compared to non-thalassemic subjects. The cause of the hypogonadism observed in thalassemia patients is multifactorial and could be related to increased iron stores in gonadotrophic or pituitary tissues $[15,16]$; a condition that predisposes these tissues to peroxidative damage caused by the generation of free oxygen radicals through fenton reactions [17]. The observed hypogonadism may be involved in the disruption of bone homeostasis in TI. Several reports showed that estrogen, through its interaction with estrogen receptor $\alpha$, increases the transcript and protein levels of OPG [18]. Moreover, estrogen was reported to decrease the expression levels of RANKL [19]. The above changes are predicted to cause disruption of bone remodeling in TI with a resulting increase in the rate of bone resorption and a decrease in bone formation; pathophysiological changes that are consistent with our findings that CTX (a marker of bone resorption) serum levels are significantly increased in TI patients while P1NP (a marker of bone formation) levels are significantly reduced. Whether a reduction in sex steroid hormone levels is the driving force for bone loss in TI patients remains to be determined, nonetheless our findings support the use of selective estrogen receptor modulators (SERMs) for the treatment/prevention of bone loss in TI [20].

We also found that RANKL serum levels were significantly higher in TI patients compared to the non-thalassemic controls, while OPG levels were significantly lower in TI patients. Furthermore, we found that RANKL was a significant predictor of the levels of CTX and P1NP while OPG was a significant predictor of P1NP serum levels. These findings support that bone remodeling in TI patients may be dysregulated because of an imbalance between the rate of bone formation and bone resorption. It appears that there is a decrease in the rate of bone formation accompanied with an increase in the rate of bone resorption with a net result of bone loss in TI. We also demonstrated that RANKL, OPG or RANKL/OPG ratio could serve as potential serum bone-turnover markers in TI. 
In addition to the biochemical changes above, we found that EPO levels increased in thalassemic patients. We also found that EPO serum levels were a significant predictor of changes in both CTX and P1NP levels. The increase we observed in EPO levels is presumably reflective of an increase in tissue hypoxia resulting from the anemia that accompanies thalassemia. In this case, EPO stimulates the bone marrow to produce more red blood cells to compensate for the low hemoglobin that accompanies thalassemia. An increase in EPO serum levels may also contribute to the bone loss observed in TI where erythroid hyperplasia, caused by increased EPO levels, may cause cortical thinning and an increase in bone fragility [21].

It is well established that the clinical/complication profile of TI differs from TM [22]. For example, unlike patients diagnosed with TM, TI patients present with the disease in later childhood or early adulthood and do not require regular blood transfusion to manage their anemia $[22,23]$. Distinction needs to be made between TI and TM patients to spare TI patients from the side effects associated with the often unnecessary blood transfusions [24]. Distinction is purely made on clinical basis, although genotype/phenotype associations in TI were described [25]. These associations support the feasibility of finding genetic/biochemical markers that distinguish between the two disease states. Given our findings that the blood levels of the sex steroid hormones, EPO, OPG and RANKL change in TI, it remains to be determined whether measurement of these markers could help distinguish between TI and TM. However, this requires the recruitment of both TM and TI patients followed by the measurement of the above markers; a future direction of our research group.

In conclusion, up to our knowledge, our research team is the first to report changes in the serum levels sex steroid hormones, EPO, OPG and RANKL in TI patients compared to non-thalassemic controls. The translational relevance of these findings to the treatment of osteoporosis in TI and the distinction between TI and TM still needs to be determined.

\section{Limitations}

The sample size may limit the statistical power of this investigation and further validation studies on a larger group of patients is warranted to confirm our findings. Additionally, we failed to include a direct measurement of bone density using dual-energy X-ray absorptiometry (DEXA) [26]. Instead, we relied on indirect evaluation of bone density inferred by measurements of the bone turnover markers CTX and P1NP. The lack of such data prevented us from correlating the serum levels of the sex steroid hormones or EPO with the severity of the disease.

\section{Abbreviations}

TI: thalassemia intermedia; TM: $\beta$ thalassemia major; EPO: erythropoietin; CTX: carboxy-terminal collagen cross links; P1NP: N-terminal propeptide of type 1 collagen; RANKL: receptor activator of NF-kappaB ligand; RANK: receptor activator of NF-kappaB; OPG: Osteoprotegerin; ELISA: enzyme-linked immunosorbent assay; SPSS: statistical package for social studies; SERM: selective estrogen receptor modulators; DEXA: dual-energy X-ray absorptiometry.

\section{Authors' contributions \\ All the authors participated in the design, analysis of the data, and final review of the manuscript. MAA NB and MB conceived the study; MB and SA helped in data collection; YSK and RS performed the statistical analysis; SA performed all the biochemical measurements; MAA and NB drafted the manuscript. All authors read and approved the final manuscript.}

\section{Author details}

${ }^{1}$ Department of Physiology and Biochemistry, School of Medicine, Jordan University of Science and Technology, Irbid 221 10, Jordan. ${ }^{2}$ Department of Family Medicine and Public Health, Jordan University of Science and Technology, Irbid, Jordan. ${ }^{3}$ Department of Pediatrics, Princess Rahma Hospital, Irbid, Jordan.

\section{Acknowledgements}

Not applicable.

\section{Competing interests}

The authors declare that they have no competing interests.

\section{Availability of data and materials}

The datasets generated and/or analysed during the current study are available from the corresponding author on reasonable request.

\section{Consent for publication \\ Not applicable.}

\section{Ethics approval and consent to participate}

Procedures performed in this study required the submission and approval of the study protocol to the ethical review boards of Jordan University of Science and Technology and Princess Rahma Hospital. All the procedures described in this study were in accordance with the ethical standards of Jordan University of Science and Technology and Princess Rahma Hospital institutional review board and with the 1964 Helsinki declaration and its later amendments or comparable ethical standards. A written Informed consent was obtained from all individual participants or from their legal guardians if the participant was under 16 years of age.

\section{Funding}

This study was supported by the Deanship of Research at Jordan University of Science and Technology (139/2015). The funding body was not involved in designing the study, the collection, analysis and interpretation of the data, or writing the manuscript.

\section{Publisher's Note}

Springer Nature remains neutral with regard to jurisdictional claims in published maps and institutional affiliations.

Received: 13 March 2018 Accepted: 19 July 2018

Published online: 31 July 2018

\section{References}

1. Musallam KM, Taher AT, Rachmilewitz EA. $\beta$-thalassemia intermedia: a clinical perspective. Cold Spring Harb Perspect Med. 2012;2(7):a013482.

2. Sturgeon P, Itano HA, Bergren WR. Genetic and biochemical studies of 'intermediate' types of Cooley's anaemia. Br J Haematol. 1955;1(3):264-77.

3. Terpos E, Voskaridou E. Treatment options for thalassemia patients with osteoporosis. Ann N Y Acad Sci. 2010;1202(1):237-43.

4. Anapliotou ML, Kastanias IT, Psara P, Evangelou EA, Liparaki M, Dimitriou P. The contribution of hypogonadism to the development of osteoporosis 
in thalassaemia major: new therapeutic approaches. Clin Endocrinol. 1995;42(3):279-87.

5. Haidar R, Musallam KM, Taher AT. Bone disease and skeletal complications in patients with $\beta$ thalassemia major. Bone. 2011;48(3):425-32.

6. Napoli N, Carmina E, Bucchieri S, Sferrazza C, Rini G, Di Fede G. Low serum levels of 25-hydroxy vitamin $D$ in adults affected by thalassemia major or intermedia. Bone. 2006;38(6):888-92.

7. Eren E, Yilmaz N. Biochemical markers of bone turnover and bone mineral density in patients with $\beta$-thalassaemia major. Int J Clin Pract. 2005;59(1):46-51.

8. Vasikaran S, Eastell R, Bruyère O, Foldes AJ, Garnero P, Griesmacher A, McClung M, Morris HA, Silverman S, Trenti T, et al. Markers of bone turnover for the prediction of fracture risk and monitoring of osteoporosis treatment: a need for international reference standards. Osteoporos Int. 2011;22(2):391-420.

9. Wada T, Nakashima T, Hiroshi N, Penninger JM. RANKL-RANK signaling in osteoclastogenesis and bone disease. Trends Mol Med. 2006;12(1):17-25.

10. Wright $\mathrm{H}$, McCarthy HS, Middleton J, Marshall MJ. RANK, RANKL and osteoprotegerin in bone biology and disease. Curr Rev Musculoskelet Med. 2009;2(1):56-64.

11. Boyle WJ, Simonet WS, Lacey DL. Osteoclast differentiation and activation. Nature. 2003:423(6937):337-42.

12. Boyce BF, Xing L. The Rankl/Rank/Opg pathway. Curr Osteoporos Rep. 2007:5(3):98-104.

13. Saki N, Abroun S, Salari F, Rahim F, Shahjahani M, Javad MA. Molecular aspects of bone resorption in $\beta$-thalassemia major. Cell J (Yakhteh). 2015:17(2):193.

14. Morabito N, Gaudio A, Lasco A, Atteritano M, Pizzoleo MA, Cincotta M, La Rosa M, Guarino R, Meo A, Frisina N. Osteoprotegerin and RANKL in the pathogenesis of thalassemia-induced osteoporosis: new pieces of the puzzle. J Bone Miner Res. 2004;19(5):722-7.

15. Anapllotou ML, Kastanias IT, Psara P, Evangelou EA, Liparaki M, Dimitriou P. The contribution of hypogonadism to the development of osteoporosis in thalassaemia major: new therapeutic approaches. Clin Endocrinol. 1995;42(3):279-87.

16. Noetzli LJ, Panigrahy A, Mittelman SD, Hyderi A, Dongelyan A, Coates TD, Wood JC. Pituitary iron and volume predict hypogonadism in transfusional iron overload. Am J Hematol. 2012;87(2):167-71.

17. Emerit J, Beaumont C, Trivin F. Iron metabolism, free radicals, and oxidative injury. Biomed Pharmacother. 2001;55(6):333-9.

18. Hofbauer LC, Khosla S, Dunstan CR, Lacey DL, Spelsberg TC, Riggs BL. Estrogen stimulates gene expression and protein production of osteoprotegerin in human osteoblastic cells. Endocrinology. 1999;140(9):4367-70.

19. Aubin JE, Bonnelye E. Osteoprotegerin and its ligand: a new paradigm for regulation of osteoclastogenesis and bone resorption. Osteoporos Int. 2000;11(11):905-13.

20. Hosking D, Chilvers CE, Christiansen C, Ravn P, Wasnich R, Ross P, McClung M, Balske A, Thompson D, Daley M. Prevention of bone loss with alendronate in postmenopausal women under 60 years of age. N Engl I Med. 1998:338(8):485-92.

21. Perisano C, Marzetti E, Spinelli MS, Calla CAM, Graci C, Maccauro G. Physiopathology of bone modifications in-thalassemia. Anemia. 2012;2012:5.

22. Camaschella C, Cappellini MD. Thalassemia intermedia. Haematologica. 1995;80(1):58-68.

23. Shawky RM, Kamal TM. Thalassemia intermedia: an overview. Egypt J Med Hum Genet. 2012;13(3):245-55.

24. Taher AT, Musallam KM, Cappellini MD, Weatherall DJ. Optimal management of beta thalassaemia intermedia. Br J Haematol. 2011;152(5):512-23.

25. Galanello R, Cao A. Relationship between genotype and phenotype: thalassemia intermedia. Ann NY Acad Sci. 1998;850:325-33.

26. Bachrach L. Dual energy $X$-ray absorptiometry (DEXA) measurements of bone density and body composition: promise and pitfalls. J Pediatr Endocrinol Metab. 2000;13:983-8.
Ready to submit your research? Choose BMC and benefit from:

- fast, convenient online submission

- thorough peer review by experienced researchers in your field

- rapid publication on acceptance

- support for research data, including large and complex data types

- gold Open Access which fosters wider collaboration and increased citations

- maximum visibility for your research: over $100 \mathrm{M}$ website views per year

At BMC, research is always in progress.

Learn more biomedcentral.com/submissions 